\title{
Prevalence, trend and associated risk factors of Mother-to-Child Transmission of HIV among HIV- exposed infants
}

Gadissa Gutema ( $\sim$ gadissagutema@gmail.com )

Ethiopian Public Health Institute

Habteyes Hailu

Ethiopian Public Health Institute

Dinka Fikadu

Ethiopian Public Health Institute

Dereje Leta

Ethiopian Public Health Institute

\section{Birra Bejiga}

Ethiopian Public Health Institute

Jaleta Bulti

Ethiopian Public Health Institute

\section{Saro Abdela}

Ethiopian Public Health Institute

\section{Hassen Mamo}

Addis Ababa University

\section{Research Article}

Keywords: HIV, EID, MTCT, HIV-exposed infants

Posted Date: September 7th, 2022

DOI: https://doi.org/10.21203/rs.3.rs-1341228/v2

License: (c) (i) This work is licensed under a Creative Commons Attribution 4.0 International License.

Read Full License 


\section{Abstract \\ Background}

The Human Immunodeficiency Virus (HIV) Mother-To-Child-Transmission (MTCT) can primarily occur during pregnancy, birth and breastfeeding. However, there is limited recent evidence from large-scale study on MTCT of HIV in Ethiopia. Thus, this study was aimed to determine the prevalence, trend and associated risk factors of MTCT among HIV-exposed infants.

\section{Methodology}

: A cross-sectional study was conducted on 5,679 infants whose specimen referred to Ethiopian Public Health Institute HIV referral laboratory from January 01, 2016 to December 31, 2020. Required information was obtained from Early Infant Diagnosis (EID) database. Frequencies and percent were used to describe the distribution of the infants. Logistic regression analysis was used to identify factors associated with HIV infection. The level of significance was set at $5 \%$.

\section{Results}

The mean age of the infants was $12.64( \pm 14.62)$ weeks with 4 to 72 weeks range. Half of the infants (51.4\%) were female. Prevalence of HIV infection over the course of five years among HIV-exposed infants (HEI) was $2.6 \%$. The prevalence of MTCT decreased from $2.9 \%$ in 2016 to $0.9 \%$ in 2020 . After adjusting for covariates; infant testing after six weeks (Adjusted odds ratio (AOR) $=2.7 ; 95 \%$ confidence interval (Cl): (1.8-4.0, )) p-value $<0.001$, absence of Prevention of Mother-To-Child-Transmission (PMTCT) service $(A O R=4.6 ; 95 \% \mathrm{Cl}:(2.9-7.4))$ p-values $=0.001$, lack of obtaining nevirapine prophylaxis $(\mathrm{AOR}=2.0 ; 95 \% \mathrm{Cl}:(1.3-3.2)) \mathrm{p}$-value < 0.001, and mother HIV status before date of delivery $(\mathrm{AOR}=11$; $95 \% \mathrm{Cl}:(5.5-22.1)) p$-value $<0.001$ were significantly associated with MTCT of HIV.

\section{Conclusion}

The prevalence of MTCT of HIV is considerable. However, the prevalence was declining during the study period. Tested after six weeks for EID, unavailability of PMTCT service were the factors associated with HIV infection among HEI. Strengthen PMTCT service and early HIV screening of pregnant women are critical to reduce HIV infection among HEI.

\section{Background}

The Human Immunodeficiency Virus (HIV) can be transmitted from HIV-positive mothers to their child during pregnancy, at birth and breastfeeding which accounts for the majority of infection in children [13]. The proportion of Mother-To-Child-Transmission (MTCT) of HIV in treatment-naive pregnant women 
ranges from 15-45\%. However, antiretroviral therapy (ART), post-exposure prophylaxes and Prevention of Mother-To-Child Transmission (PMTCT) service can reduce the proportion of MTCT to less than $5 \%[2,4]$. Virological screening for exposed infants at six weeks of age or at the earliest possible stage after six week plays a great role to PMTCT $[2,5-6]$. However, only half of HIV-exposed infants (HEI) are tested within a World Health Organization (WHO) recommended age [7].

According to the United Nations Programme on Human Immunodeficiency Virus/Acquired Immunodeficiency Syndrome (UNAIDS) annual review, although different efforts were being made, about 500 children under 15 years of age were infected with HIV per a day in 2018 globally. In the same year, it was estimated that 1.7 million children live with HIV and 100,000 children died due to Acquired Immune Deficiency Syndrome (AIDS), and 160,000 acquired new HIV infection [8]. Furthermore, each year over half a million new born are infected with HIV in sub-Saharan Africa through MTCT [9].

An estimate indicates that, in 2010; 6,200 children were newly infected with HIV in Ethiopia, while in 2015; 3,300 and in 2018; 2,700. In addition, in 2010; 5,400 children died due to AIDS, whereas in 2015; 2,400 and in 2018;1,800 children were died [8].

Despite, ART service for children was launched in 2005 in Ethiopia and national PMTCT program was started in 2001 , only 23,400 of children were on ART in 2017 [10]. Thus, ART coverage for children remains low (23.5\%) in Ethiopia [2]. While, more than $92 \%$ of pregnant women living with HIV access preventive prophylaxes in 2018 in Ethiopia. Laboratory test coverage of Early Infant Diagnosis (EID) was $68 \%$ in 2018. Furthermore, the rate of MTCT decreased from 18\% in 2010 to $9 \%$ in 2018 [8].

Local studies reported from Ethiopia indicated that considerable infants born from HIV positive mother are infected [10-12]. For instance, study reported from Amhara regional state has shown $2.3 \%$ infants born from HIV positive mother are infected with HIV [11]. An another study reported from Amhara regional state has shown that $10.1 \%$ of infants born from HIV positive mother are infected with HIV [12]. Furthermore, a study reported from Dire Dawa revealed that $15.7 \%$ of infant born from HIV positive mothers were HIV positive [10]. Moreover, a study reported from Addis Ababa indicated that $2 \%$ of infants were HIV positive at 6 week of age, while $4 \%$ were HIV positive at 18 month of age [13]. Another study reported from Bahir-Dar indicated that $5.8 \%$ of infants born from HIV positive mothers are infected [14]. Furthermore, reviews from Ethiopia have shown $11.4 \%$ and $9.9 \%$ pooled prevalence of MTCT in Ethiopia [15-16].

Several factors are associated with HIV infection among infants born from HIV positive mothers. For example delayed diagnosis, failure to receive either ART or prophylaxis during pregnancy, breastfeeding, and short duration since prophylaxes started during pregnancy are significantly associated with HIV infection of HEI [12]. Moreover, infants not receiving ART prophylaxis at birth, mixed feeding practices, and mother-child pairs not receiving prophylaxes are also significantly associated with MTCT [13].

In general, MTCT is decreasing globally. A study reported from Burkina Faso indicated HIV transmission rate decreased from $10.4 \%$ in 2006 to $0 \%$ in 2015 [17]. In Kenya, the positive rate declined from $17.0 \%$ in 
2007 to $7.2 \%$ in 2013 [18]. Moreover, the burden of MTCT is decreased in Vietnam from $27.9 \%$ in 2007 to $0 \%$ in 2018 [19].

Global plan provides the foundation for country-led movement towards the elimination of new HIV infections among children. However, Ethiopia is among the ten countries in the world with the highest burden of HIV infections among children [4]. Although, there are small scales local studies conducted on MTCT in Ethiopia, there is limited information from large scale samples on the burden and factors associated with HIV infection among infants born from HIV positive mothers. Thus, this study was aimed to estimate the prevalence, past five-year trend (2016-2020) and factors associated with HIV in HEls from large sample.

\section{Methods}

A cross-sectional study was conducted to determine prevalence, trend, and factors associated with HIV infection among infants exposed to HIV in Ethiopia. Ethiopian Public Health Institute (EPHI) is a national biomedical and public health research institute. It is also a national referral laboratory. National HIV referral laboratory is one of biomedical laboratories found in EPHI, and the molecular laboratory in HIV referral laboratory has accredited ISO 15189; 2012 by national accreditation organization. It receives specimen for HIV EID from every part of Ethiopia where the service is not available. Dried Blood Spot (DBS) specimen referred to the laboratory for the past 16 years. Five-year data were extracted from EID database in the period of January 01, 2016 to December 31, 2020 for this study (Fig. 1). The study population of this study was all infants born from HIV positive mother and who attended health facilities network for EID testing.

\section{Inclusion and Exclusion criteria}

Children with full EID results with key variables were included in the study. However, children with incomplete record and indeterminate results were excluded.

\section{Sample size calculation and sampling}

A total of 6,835 infants were referred to EPHI HIV national laboratory for EID test in the study period. Of these, a total of 5,679 infants were included in the study. Thus, since all infants with complete data were included to this study, special sample size calculation and sampling technique were not employed.

\section{Data Collection}

Data of infants were collected from EID database on sex, age in week, HIV status, feeding practice, mother ART status at delivery, and PMTCT intervention given to infant and mother. The outcome variable HIV infection was confirmed by automated Polymerase Chain Reaction (PCR) using COBAS AmpliPrep/COBAS TaqMan (Roche CAP/CTM) HIV-1 proviral Deoxyribonucleic Acid (DNA) qualitative detection technique.

\section{Statistical analyses}


The data was reviewed and checked for completeness. Descriptive statistics was used to show participants distribution. Logistic regression model was applied to determine factors associated with HIV infection among infants. Variables scored $p$-value $<0.2$ during bivariate analysis were included into multivariate analysis model. Odds ratios (ORs) with $95 \%$ confidence intervals (Cls) were reported to show strength of association and precision level was set at $5 \%$.

\section{Results}

\section{General characteristics of study participants}

A data on $5,679 \mathrm{HEl}$ was included in this analysis. The mean age of the infants was $12.64( \pm 14.62)$ week with age range 4 to 72 weeks. The proportion of infants tested for HIV at WHO recommended age (age $\leq$ 6 weeks) was $56.5 \%$ [Table 1]. Half (51.4\%) of the infants were female and $57 \%$ were residents of Addis Ababa. A total $95.4 \%$ enrolled infants attended PMTCT service. Of the total infants received PMTCT service $95.3 \%$ were obtained Nevirapine prophylaxis at birth and until six weeks after birth. 
Table 1

Socio-demographic and general characteristics of HIV exposed infants

\begin{tabular}{|c|c|c|c|}
\hline Variable & & Frequency & Percent \\
\hline & Female & 2921 & 51.4 \\
\hline \multirow[t]{2}{*}{ Sex } & Male & 2758 & 48.6 \\
\hline & $\leq 6$ weeks & 3206 & 56.5 \\
\hline \multirow[t]{5}{*}{ Age } & $>6$ weeks & 2473 & 43.5 \\
\hline & Addis Ababa & 3239 & 57.0 \\
\hline & Afar & 09 & 0.2 \\
\hline & Amhara & 197 & 3.5 \\
\hline & Benishangul Gumuz & 06 & 0.1 \\
\hline \multirow[t]{5}{*}{ Region of test } & Gambella & 466 & 8.2 \\
\hline & Oromia & 1055 & 18.6 \\
\hline & SNNPR & 75 & 1.3 \\
\hline & Tigray & 632 & 11.1 \\
\hline & Exclusive breast feeding & 4150 & 73.1 \\
\hline Infant feeding & Replacement feeding & 1529 & 26.9 \\
\hline \multicolumn{4}{|l|}{ Practice } \\
\hline \multirow[t]{2}{*}{ Intervention given to infant in PMTCT } & Present & 5420 & 95.4 \\
\hline & Absent & 259 & 4.6 \\
\hline \multirow{2}{*}{$\begin{array}{l}\text { Infant received Nevirapine prophylaxis } \\
\text { therapy }\end{array}$} & Yes & 5166 & 95.3 \\
\hline & No & 254 & 4.7 \\
\hline \multirow[t]{3}{*}{ Mother ART Status During delivery } & $\begin{array}{l}\text { Newly initiated up on } \\
\text { delivery }\end{array}$ & 1478 & 26.0 \\
\hline & Previously on ART & 4145 & 73.0 \\
\hline & Status unknown & 56 & 1.0 \\
\hline \multirow[t]{2}{*}{ Prevalence of HIV } & Negative & 5533 & 97.4 \\
\hline & Positive & 146 & 2.6 \\
\hline
\end{tabular}




\section{HIV prevalence and trends in infants born from HIV positive mothers}

The overall prevalence of HIV infection in the past-five year among infants born from HIV positive mothers was $2.6 \%$. The highest prevalence (3.9\%) of HIV infection was observed in Oromia Regional State and the lowest $(0.0 \%)$ in Afar and Benishangul Gumuz Regional States [Table 1]. In general, the prevalence of HIV infection decreased from $2.9 \%$ in 2016 to $0.9 \%$ in 2020 . However, the prevalence of HIV infection among infants increased in 2018 (5.6\%) [Fig. 2].

\section{Factors associated with HIV infection}

Being tested after 6 weeks of age (crude odds ratio (COR) $=3.5 ; 95 \%(C l):(2.5-5.1)$, $p$-value $<0.001)$, absence of PMTCT service (COR $=10.3 ; 95 \% \mathrm{Cl}$ : (7.1-15.0), $p$-value $<0.001)$, lack of obtaining nevirapine prophylaxis $(C O R=5.5 ; 95 \% \mathrm{Cl}$ : (3.9-7.9), $p$-value $<0.001)$ and mother's ART status unknown during delivery $(C O R=3.4 ; 95 \% \mathrm{Cl}:(2.2-5.5)$, $p$-value $<0.001)$ were significantly associated with HIV infection during bivariate analysis [Table 2].

Based on multivariate analysis, being tested after 6 weeks of age (Adjusted odds ratio $(A O R)=2.7 ; 95 \%$ Cl: (1.8-4.0), $p$-value $<0.001)$, absence of PMTCT service (AOR $=4.6 ; 95 \% \mathrm{Cl}$ : $(2.9-7.4), p$-value $=0.001)$, lack of obtaining nevirapine prophylaxis (AOR $=2.0 ; 95 \% \mathrm{Cl}$ : $(1.3-3.2), p$-value $<0.001)$ and mother ART status unknown during delivery $(\mathrm{AOR}=11 ; 95 \% \mathrm{Cl}:(5.5-22.1), p$-value $<0.001)$ were significantly associated with HIV infection after adjusted for potential confounders [Table 2]. 
Table 2

Bivariate and Multivariate Analysis of factors associated with HIV positivity

\begin{tabular}{|c|c|c|c|c|c|c|c|}
\hline & Variables & EID PCR & $\begin{array}{l}\text { Test } \\
\text { results }\end{array}$ & $\begin{array}{l}\text { COR } \\
(95 \% \mathrm{Cl})\end{array}$ & $\begin{array}{l}p- \\
\text { value }\end{array}$ & $\begin{array}{l}\mathrm{AOR}(95 \% \\
\mathrm{Cl})\end{array}$ & $p$-value \\
\hline & & $\begin{array}{l}\text { Negative } \\
(\%)\end{array}$ & $\begin{array}{l}\text { Positive } \\
\text { (\%) }\end{array}$ & & & & \\
\hline \multirow[t]{2}{*}{ Sex } & Female & $\begin{array}{l}2683 \\
(97.3)\end{array}$ & $75(2.7)$ & 1 & 0.492 & & \\
\hline & Male & $\begin{array}{l}2850 \\
(97.6)\end{array}$ & $71(2.4)$ & $\begin{array}{l}0.9(0.6- \\
1.2)\end{array}$ & & & \\
\hline \multirow[t]{2}{*}{ Age group } & $\begin{array}{l}\text { Referred at } \\
\leq 6 \text { weeks }\end{array}$ & $\begin{array}{l}3166 \\
(98.8)\end{array}$ & $40(1.2)$ & 1 & & 1 & \\
\hline & $\begin{array}{l}\text { Referred }>6 \\
\text { weeks }\end{array}$ & $\begin{array}{l}2367 \\
(95.7)\end{array}$ & $\begin{array}{l}106 \\
(4.3)\end{array}$ & $\begin{array}{l}3.5(2.5- \\
5.1)\end{array}$ & $\begin{array}{l}<.001 \\
0 .\end{array}$ & $\begin{array}{l}2.7(1.8- \\
4.0)^{\star \star}\end{array}$ & $<0.001$ \\
\hline $\begin{array}{l}\text { Infant } \\
\text { feeding }\end{array}$ & $\begin{array}{l}\text { Exclusive } \\
\text { breast } \\
\text { feeding }\end{array}$ & $4041(97.4)$ & $\begin{array}{l}109 \\
(2.6)\end{array}$ & 1 & & & \\
\hline practice & $\begin{array}{l}\text { Replacement } \\
\text { feeding }\end{array}$ & $\begin{array}{l}1492 \\
(97.6)\end{array}$ & $37(2.4)$ & $\begin{array}{l}1.1(0.8- \\
1.6)\end{array}$ & 0.663 & & \\
\hline \multirow{2}{*}{$\begin{array}{l}\text { Intervention } \\
\text { given to } \\
\text { infant in } \\
\text { PMTCT }\end{array}$} & Present & $5317(98.1)$ & 103(1.9) & 1 & & 1 & \\
\hline & Absent & $216(83.4)$ & $43(16.6)$ & $\begin{array}{l}10.3(7.0- \\
15.0)\end{array}$ & $\begin{array}{l}< \\
0.001\end{array}$ & $\begin{array}{l}4.6(2.9- \\
7.4)^{\star \star}\end{array}$ & 0.001 \\
\hline \multirow{2}{*}{$\begin{array}{l}\text { Infant } \\
\text { received } \\
\text { Nevirapine } \\
\text { prophylaxis } \\
\text { therapy }\end{array}$} & Yes & $\begin{array}{l}5062 \\
(98.0)\end{array}$ & $\begin{array}{l}104 \\
(2.0)\end{array}$ & 1 & & 1 & \\
\hline & No & $464(90.4)$ & $49(9.6)$ & $\begin{array}{l}5.5(3.9- \\
7.9)\end{array}$ & $\begin{array}{l}< \\
0.001\end{array}$ & $\begin{array}{l}2.0(1.3- \\
3.2) * *\end{array}$ & $<0.001$ \\
\hline \multirow[t]{3}{*}{$\begin{array}{l}\text { Mother ART } \\
\text { status }\end{array}$} & $\begin{array}{l}\text { Previously } \\
\text { on ART }\end{array}$ & $1445(97.8)$ & $33(2.2)$ & 1 & & 1 & \\
\hline & $\begin{array}{l}\text { Newly } \\
\text { initiated up } \\
\text { on delivery }\end{array}$ & $4057(97.9)$ & $88(2.1)$ & $\begin{array}{l}3.6(2.5- \\
6.2)\end{array}$ & $\begin{array}{l}< \\
0.001\end{array}$ & $\begin{array}{l}12.9(6.1- \\
26.9) * *\end{array}$ & $<0.001$ \\
\hline & $\begin{array}{l}\text { Status not } \\
\text { known }\end{array}$ & $31(55.4)$ & $25(44.6)$ & $\begin{array}{l}3.4(2.2- \\
5.5)\end{array}$ & $<.001$ & $\begin{array}{l}11.0(5.5- \\
22.1) * *\end{array}$ & $<0.001$ \\
\hline
\end{tabular}




\section{Discussion}

This study aims to determine the prevalence of HIV in HEI, the risk factors associated with HIV infection, and five-year trend in HEl. The prevalence of HIV in HEI was $2.6 \%$. The prevalence decreased across the five-year, although the highest was observed in 2018. Being tested after 6 weeks of age; absence of PMTCT service; lack of obtaining nevirapine prophylaxis, and mother ART status unknown during delivery were significantly associated with HIV infection after adjusted for potential confounders.

The current study has shown that HIV infection among infants born from HIV positive mothers is higher than WHO recommendation on HIV which indicates zero new HIV infections in infants born from HIV positive mothers by 2020 [5]. However, the present study prevalence is nearly similar with UNAIDS WHO strategy on HIV elimination in which the prevalence of HIV should be $5.0 \%$ or less among breastfeeding women and $2.0 \%$ or less among non-breastfeeding by 2020 [20]. Moreover, the study reported from Adama, central Ethiopia, indicated lower (0.4\%) prevalence than our study [21]. This difference most probably due to study population, sample size and study design. In the case of study reported from Adama the study design was retrospective cohort which sampled based on the exposure status. In addition WHO estimation of 2018 shown similar prevalence (2.8\%) [3] with our result.

In contrast to our finding other studies from different parts of the world as well as Ethiopia obtained high prevalence [11, 22-29]. Furthermore, a study reported from Addis Ababa indicated higher prevalence (4.2\%) of HIV infection in HEl [13] than the current study. This difference might be due to sample size, study period, PMTCT service accessibility and strength. Moreover, the study reported from Jimma, southwest Ethiopia, indicated the highest prevalence of HIV infection among HEl in which the prevalence was $17 \%$ [30]. This difference might be because of the difference in study period, PMTCT strategies at study period, sample size and data source. The data source in the Jimma study was patients' treatment care at health facilities, and the data collection period was older than our study period. However, the data source for our study was the national early infant diagnosis database.

The prevalence of HIV in HEI has shown a decreasing tendency across the five past years. However, the highest prevalence (5.6\%) was reported in 2018. This could be due to a lot of records were excluded from the analysis due to incomplete data on important variables in 2018. The decrease in trend on HIV infection across the five years is similar to a study reported from China in which the trend showed $48.5 \%$ prevalence reduction in the year 2014 to 2019 [31]. Similarly, the study reported from Burkina-Faso indicated reduction of HIV transmission prevalence from 10.4\% in 2006 to $0.0 \%$ in 2015 [17]. Moreover, the study reported from Vietnam indicated the reduction of HIV MTCT from $27.9 \%$ in 2007 to $0 \%$ in 2018 [19]. In addition, a study reported from Kenya indicated gradual reduction from $19.8 \%$ in 2007 to $7.2 \%$ in 2013 [18].

Being tested after 6 weeks of age was significantly increased the risk of HIV vertical transmission. The odds of HIV infection was 2.7 times higher in infants tested after six weeks of age compared to those who were tested before six weeks of age. This finding is similar with the findings reported by previous studies from different countries [14, 24, 29, 32]. Similarly, the finding reported from Kenya indicated that 
infants tested after 6 weeks of age had $6.3 \%$ chance of getting HIV infection [22]. The possible explanation for the high positive rate among infants tested after six weeks of age might be lack of prophylaxis. In contrast, a study reported from Dire Dawa showed that age of infants was not significantly associated with MTCT of HIV [10]. This difference might be because of the relatively smaller sample size used in the study from Dire Dawa.

It was found that infants who did not receive PMTCT service had 4.6 times higher risk of HIV infection than those who received the service. This result was in-line with the finding reported by Wudineh et al., 2016 [10]. In addition, in our study infants who did not receive nevirapine prophylaxis had 2 times higher risk of HIV infection compared to those who obtained the prophylaxis. This result was similar with previous studies reported from different settings [10,13-14, 19], 26, 29]. Moreover, in-line with our result, findings reported by review studies indicated that infants on nevirapine prophylaxes were at lesser risk of HIV infection than those who missed the service $[16,25]$. These indicate that nevirapine prophylaxis could prevent MTCT of HIV during breastfeeding. This might be due to the viral suppression effect of nevirapine.

Mothers' unknown ART status during delivery and newly initiated ART at delivery were significantly associated with HIV infection among HEl. This corresponds with the previously reported studies from different areas $[10,19,22,26,30-32]$. This could be due to viral suppression of the mother as a result of ART.

\section{Limitations of the study}

The study has a large sample size allowing for stable estimates and evaluation of factors associated with infant HIV transmission. Nevertheless, this study had some limitations. As the data of this study was collected from existing EID database, some variables such as duration on ART, CD4 count, and other clinical data were missing. There were also data missing which could increase or decrease potential risk factors. Furthermore, the data lacks generalization across all regions. These limitations might have underestimated or overestimated the proportion of MTCT and risks associated with MTCT of HIV. In addition, there are no repeat tested infants which would reflect time of HIV transmission.

\section{Conclusions And Recommendation}

The prevalence of MTCT of HIV is considerable in Ethiopia. Being tested after 6 weeks of age; absence of PMTCT service; lack of obtaining nevirapine prophylaxis; and unknown mother ART status during delivery were significantly associated with HIV infection. Strengthen PMTCT service and early HIV screening program are required to achieve nationally and internationally set targets to reduce MTCT of HIV.

\section{Abbreviations}

AIDS: Acquired Immunodeficiency Syndrome; AOR: Adjusted Odds Ratio; ART: Antiretroviral Therapy; ARV: Antiretroviral; Cl: Confidence Interval; COR: Crude Odds Ratio; DBS: Dried Blood Spot; DNA: 
Deoxyribonucleic Acid; EID: Early Infant Diagnosis; EPHI: Ethiopian Public Health Institute; HEl: HIVExposed Infant; HIV: Human Immunodeficiency Virus; MTCT: Mother -To-Child Transmission; PCR:

Polymerase Chain Reaction; PMTCT: Prevention Of Mother-To-Child Transmission; RNA: Ribonucleic Acid; UNAIDS: United Nations Programme on Human Immunodeficiency Virus/Acquired Immunodeficiency Syndrome; WHO: World Health Organization

\section{Declarations}

\section{Ethical approval and consent to participants}

This study was conducted on the early infant diagnosis (EID) program data. The data was extracted from routinely collected laboratory test results at Ethiopian Public Health Institute (EPHI), National HIV Reference Laboratory. Waiver for ethical approval and informed consent were obtained from EPHI Institutional Review Board. This study was conducted in accordance with Helsinki Declaration principles.

\section{Consent for publication}

Not applicable

\section{Availability of data and materials}

The data used for this study can be available from the corresponding author on reasonable request and with the permission of EPHI.

\section{Competing interest}

The authors declare that they have no competing interests in this section.

\section{Funding}

For this study, the authors did not receive any funding.

\section{Authors' contributions}

G.G. has participated in the design, coordination of the study, data collection, analysis, and interpretation. H.H. has contributed to the analysis and critically reviewed the manuscript. D.F. has contributed to the write-up, analysis, and review. D.L. has contributed to data collection, analysis, and manuscript preparation. B.B. has contributed to manuscript preparation, analysis, and review. J.B. has contributed to 
editing, reviewing, and supervising the study. S.A. has reviewed and supervised the study. H.M. has supervised the study, and critically reviewed the manuscript. All authors reviewed the manuscript.

\section{Acknowledgments}

We are grateful in extending our thanks to Mr. Tolosa Bedada and Mr. Amanuel Getachew for helping us during data extraction and statistical analysis.

\section{References}

1. Malyuta R, Newell M, Ostergren $M$, Thorne $C$, and Zhilka N. Prevention of mother-to child transmission of HIV infection: Ukraine experience to date. Eur. J. Public Health. 2006; 16(2):123-127.

2. Ministry of Health, "National Guidelines for Comprehensive HIV Prevention, Care and Treatment," Federal Ministry Heal. 2017:13-30.

3. World Health Organization. Prevention of mother-to-child transmission (PMTCT) of HIV. WHO. 2018.

4. United Nations Acquired Immunodeficiency Syndrome. Global plan towards the elimination of new HIV infections among children by 2015 and keeping their mothers alive. UNAIDS. 2015

5. Global AIDS Monitoring 2019. Glob. AIDS Monit. 2019.

6. Federal Minister of Health. National Consolidated Guidelines for Comprehensive HIV Prevention, Care and treatment. Fmoh. 2018: 1-238.

7. United Nations Children's Fund, For Every Child, end AIDS - Seventh Stocktaking Report. UNICEF. 2016.

8. Lozada JS. Joint United Nations Programme on HIV/AIDS. Encycl. Glob. Heal. 2019.

9. Kak L, Chitsike I, Luo C, and Rollins N. Prevention of mother-to-child transmission of HIV / AIDS programmes.113-126.

10. Wudineh F. and Damtew B. Mother-to-Child Transmission of HIV Infection and Its Determinants among Exposed Infants on Care and Follow-Up in Dire Dawa City, Eastern Ethiopia. AIDS Res. Treat. 2016.

11. Kassaw M, Abebe A, Abate B, Tlaye K, and Kassie A. Mother-to-child HIV transmission and its associations among exposed infants after Option $B+$ guidelines implementation in the Amhara regional state referral hospitals, Ethiopia. Int. J. Infect. Dis. 2020;95:268-275.

12. Berhan Z, Abebe F, Gedefaw M, Tesfa M, Assefa, and Y. Tafere. Risk of HIV and associated factors among infants born to HIV positive women in Amhara region, Ethiopia: A facility based retrospective study. BMC Res. Notes, 2014;7(1): 464-474.

13. Mirkuzie H. Implementation and outcomes of guideline revisions for the prevention of mother-to-child HIV transmission in Mother Support Programme, Addis Ababa, Ethiopia. PLoS One, 2018;13(6):1-15.

14. Tsehay A. Factors associated with HIV-positive sero-status among exposed infants attending care at health facilities in Bahir Dar administration, Ethiopia: Evidence from medical records. Cogent Med. 
2019;6(1).

15. Endalamaw A, Demsie A, Eshetie $S$, and Habtewold T. A systematic review and meta-analysis of vertical transmission route of HIV in Ethiopia. BMC Infect Dis. 2018;18:283.

16. Kassa G. Mother-to-child transmission of HIV infection and its associated factors in Ethiopia: A systematic review and meta-analysis. BMC Infect. Dis. 2018;18(1):1-9.

17. Linguissi L, Sagna T, Soubeiga S, Gwom L, Nkenfou C, Yeboah D, et al. Prevention of mother-to-child transmission (PMTCT) of HIV: A review of the achievements and challenges in Burkina-Faso. HIV/AIDS - Res. Palliat. Care. 2019;11:165-177.

18. Waruru A, Achia T, Muttai H, Ng'ang'a L, Gutierrez E, Ochanda B, et al. Spatial-temporal trend for mother-to-child transmission of HIV up to infancy and during pre-Option B + in western Kenya, 200713. PeerJ. 2018; 2018(3).

19. Care P, Nguyen RN, Ton QC, Tran QH, Kieu T, Nguyen L. Mother-to-Child Transmission of HIV and Its Predictors Among HIV-Exposed Infants at an Outpatient Clinic for HIV / AIDS in Vietnam. HIV/AIDS Res. Palliat. Care.2020;12:253-261.

20. UNAIDS. Start free stay free AIDS free - 2017 progress report. UNAIDS. 2017:84.

21. Chaka TE, Abebe TW, Kassa RT. Option B + prevention of mother-to-child transmission of HIV/AIDS service intervention outcomes in selected health facilities, Adama town, Ethiopia. HIV/AIDS - Res Palliat Care. 2019;11:77-82.

22. Kiplagat AB, Ngunu C, Oyugi E, Ransom J. Epidemiology of HIV Infection Among HIV-Exposed Infants, Nairobi County, Kenya, 2015. Infectious Diseases: Research and Treatment. 2020;3:10-3.

23. Dong Y, Guo W, Gui X, Liu Y, Yan Y, Feng L, et al. Preventing mother to child transmission of HIV: lessons learned from China. BMC Infect Dis. 2020;20(1):1-10.

24. Fondoh VN, and Mom NA. Mother-to-child transmission of HIV and its predictors among HIV-exposed infants at Bamenda Regional Hospital, Cameroon. Afr J Lab Med. 2017;6(1):1-7.

25. Belachew A, Tewabe T, Malede GA. Prevalence of vertical HIV infection and its risk factors among HIV exposed infants in East Africa: a systematic review and meta- analysis. Tropical Medicine and Health. 2020; 48:85.

26. Yitayew Y, Bekele D, Demissie B, Menji Z. Mother to Child Transmission of HIV and Associated Factors Among HIV Exposed Infants at Public Health. HIV/AIDS - Res Palliat Care.2019; 11:343-350.

27. Olana T, Bacha T, Worku W, Tadesse BT. Early infant diagnosis of HIV infection using DNA-PCR at a referral center: An 8 years retrospective analysis. AIDS Res Ther. 2016;13(1):1-7.

28. Care P, Kassie DG, Bogale WA, Addisu A. The Prevalence of HIV-Positive Infants Born to HIV-Positive Mothers Attended at the University of Gondar Specialized Hospital Anti-Retroviral Therapy Services, Northwest Ethiopia. HIV/AIDS - Res Palliat Care. 2020;12:135-140.

29. Tsehay AK. Risk of HIV and associated factors among infants born to HIV-positive women in northwest Ethiopia. Ethiop J Heal Dev. 2019;33(1):1-6. 
30. Birlie B, Diriba T, Sisay K, Gurmessa A, Seyoum D and Tadesse M. Mother to Child HIV Transmission and Its Predictors among HIV-Exposed Infants: A Retrospective Follow-Up Study in Southwest Ethiopia. J AIDS Clin Res. 2016;7:9

31. Zhao J, Chen Q, Fu C, Qin Q, Huang H, Feng Y, et al. Rate of the HIV Transmission and Associated Factors among HIV-Exposed Infants in Guangxi, China: 2014-2019. AIDS Res Hum Retroviruses. 2020;36(8):647-55.

32. Berhan Z, Abebe F, Gedefaw M, Tesfa M. Prevalence of HIV and Associated Factors among Infants Born to HIV Positive Women in Amhara Region, Ethiopia. Int J Clin Med. 2014;5(8):464-74.

\section{Figures}

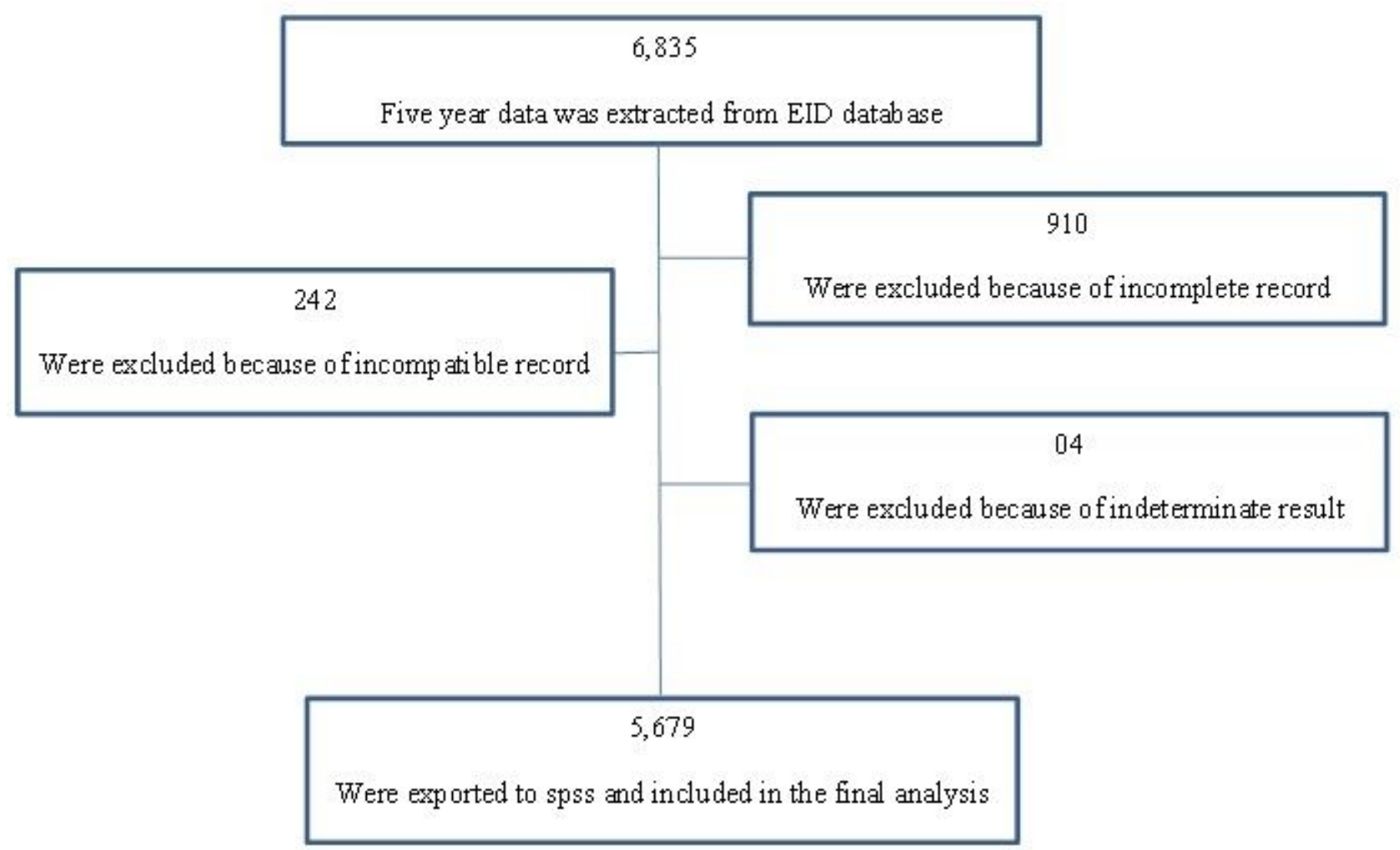

\section{Figure 1}

\section{Data extraction work flow}




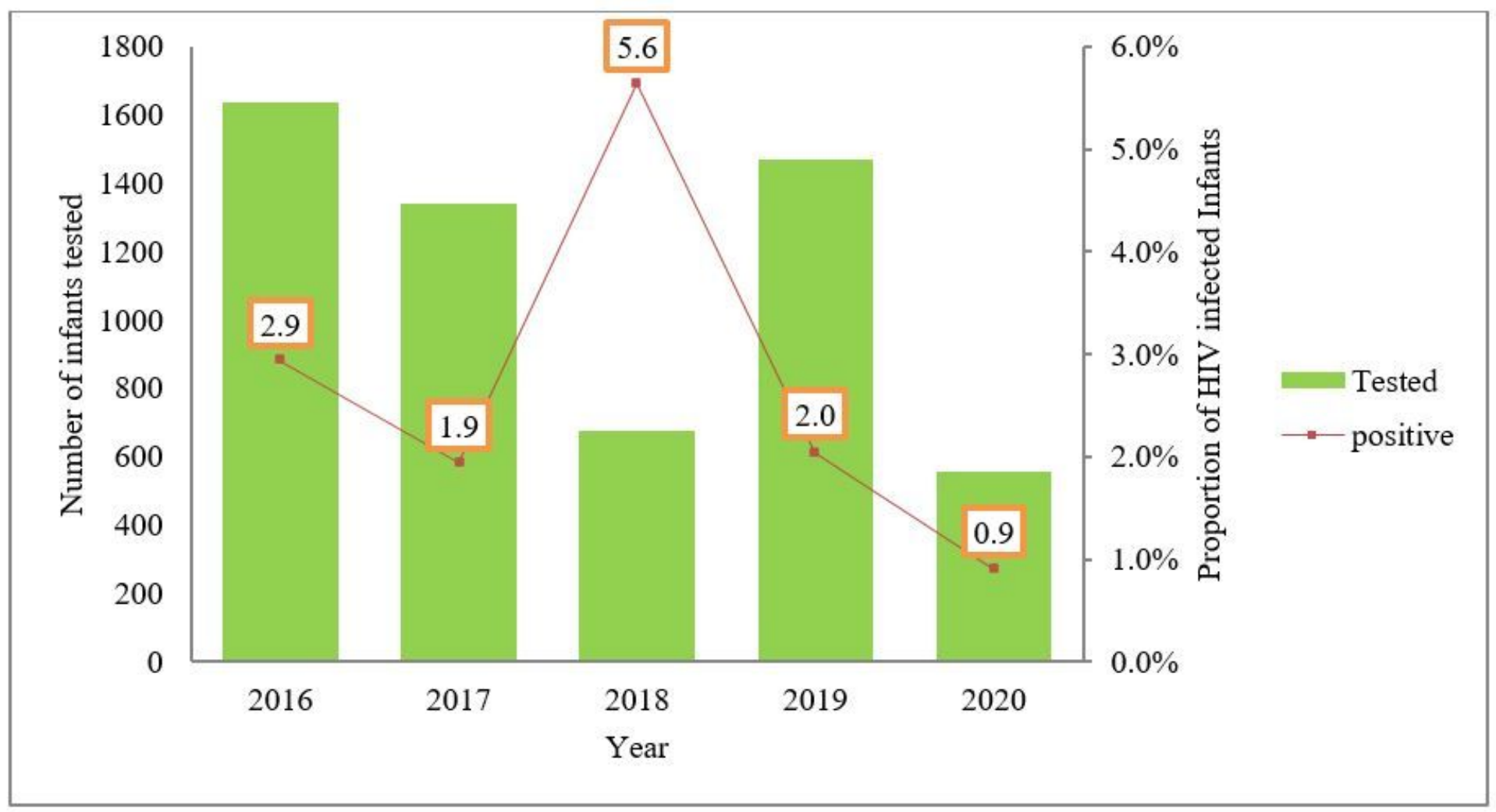

Figure 2

\section{Trends of HIV-1 EID and MTCT rate}

